Portland State University

PDXScholar

\title{
A Descriptive Study of the Relationship Between Age and Problems Expressed by Women Seeking Out- Patient Mental Health Services
}

\author{
Linda M. Rodgers \\ Portland State University \\ Joyce Carey \\ Portland State University
}

Follow this and additional works at: https://pdxscholar.library.pdx.edu/open_access_etds

Part of the Developmental Psychology Commons, Psychiatric and Mental Health Commons, and the Women's Health Commons

Let us know how access to this document benefits you.

\section{Recommended Citation}

Rodgers, Linda M. and Carey, Joyce, "A Descriptive Study of the Relationship Between Age and Problems Expressed by Women Seeking Out-Patient Mental Health Services" (1978). Dissertations and Theses. Paper 2826.

https://doi.org/10.15760/etd.2820

This Thesis is brought to you for free and open access. It has been accepted for inclusion in Dissertations and Theses by an authorized administrator of PDXScholar. Please contact us if we can make this document more accessible: pdxscholar@pdx.edu. 
A DESCRIPTIVE STUDY OF THE RELATIONSHIP BETWEEN AGE AND PROBLEMS EXPRESSED BY WOMEN SEEKING OUT-PATIENT MENTAI HEALTH SERVICES

\section{by}

Linda M. Rodgers

Joyce Carey

A practicum submitted in partial fulfillment of the requirement for the degree of

MASTER Of SOCIAL WORK

Portland State University

1978 
TO THE OFFICE OF GRADUATE STUDIES AND RESEARCH:

The advisor to Linda M. Rodgers and Joyce Carey approves the practicum presented May 19, 1978. 
TABLE OF CONTENTS

PAGE

LIST OF TABLES

CHAPTER

I INTRODUCTION • • . . . . . . . . . . . I

il SURVEY OF THE LITERATURE . . . . . . . . . 3

History and Terminology . . . . . . 3

Theories of Adult Development . . . . 4

III RESEARCH DESIGN AND METHODOLOGY . • • . . 12

Introduction . . . . . . . . . 12

Client Population . . . . . . . 12

Instrument . . . . . . . . . 12

Timing . . . . . . . . . . . 15

Setting . . . . . . . . . . . 15

Procedure . . . . . . . . . 16

IV FINDINGS . . . . . . . . . . . . . . 19

Introduction . . . . . . . . . 19

Description of Sample . . . . . . 19

Data Results . . . . . . . . . 22

Age

Other Variables

Income

Marital Status

Employment Status

Number of Children 
$\mathrm{V}$ CONCLUSIONS AND RECOMMENDATIONS • • • . . 35

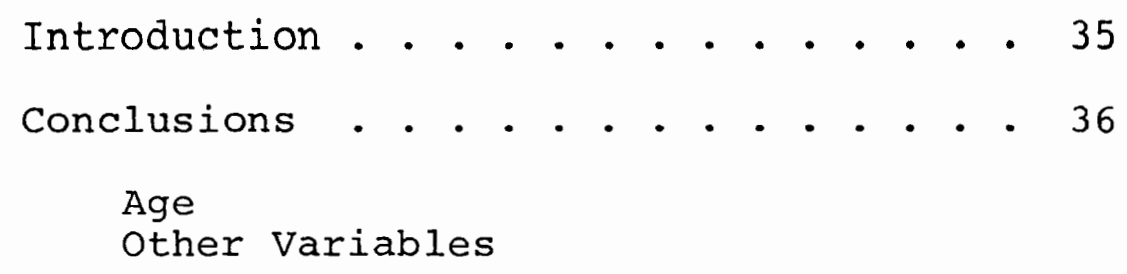




\section{LIST OF TABLES}

TABLE

PAGE

I Description of Income Distribution . . . . 20

II Description of Marital Status . . . . . . 20

II Description of Employment Status . . . . . 21

IV Description of Number of Children . . . . . 21

$\mathrm{V}$ Mean Number of Total and Circled

Responses According to Problem

Area For 20-29 Year old Women . . . . 23

VI Mean Number of Total and Circled

Responses According to Problem

Area For 40-49 Year old Women . . . . 25

VII Highest and Lowest Mean Number of

Total and Circled Responses

According to Problem Area and

Income - . . . . . . . . . . . 27

VIII Highest and Lowest Mean Number of

Total and Circled Responses

According to Problem Area and

Marital Status . . . . . . . . . 29

IX Highest and Lowest Mean Number of

Total and Circled Responses

According to Problem Area and

Employment Status . • . . . . . 32 
$\mathrm{X}$ Highest and Lowest Mean Number of

Total and Circled Responses

According to Problem Area and

Number of Children . . . . . . . 33 
CHAPTER I

\section{INTRODUCTION}

The purpose of this study is to provide a descriptive analysis of the problems presented by a specific group of women seeking out-patient mental health treatment and to relate these problems to the onotgenetic (age-related) developmental issues presented in a study of the literature. The researchers involvement in this area developed from interest in current literature on adult development, and a personal commitment to life-long growth and acceptance of the inherent changes. In order to investigate whether developmental issues exist for this group of women, and if so to describe them, two distinct age groups--the decades of the $20^{\prime} \mathrm{s}$ and the $40^{\prime} \mathrm{s}--$ were chosen as the focus of this study.

The researchers elected to study women due to personal interest, and were intrigued by the fact that women are disproportionately represented in the client populations of out-patient mental health agencies. The decades of the 20 's and $40^{\prime}$ 's were selected because the literature indicated changes in developmental tasks over time, and distinct and separate age groupings were seen as a way to highlight possible differences. Out-patient mental health centers represent one place where women experiencing problems in living 
may turn for held and were therefore chosen as data collection points. Furthermore, the researchers are involved in a specialized training project concerning community mental health issues, are presently practitioners in the outpatient mental health system, and view this research as a means of expanding awareness, increasing professional knowledge base, and contributing to program development. 
SURVEY OF THE LITERATURE

HISTORY AND TERMINOLOGY

Interest in the developmental process is probably as old as human existence with written records dating back as early as Ancient Greece and Rome. ${ }^{1}$ The focus of attention has concentrated largely on the period of most rapid and dramatic developmental changes, which is youth. Concern with the characteristics and changes during adult life is a more recent phenomenon dating largely from the early twentieth century. ${ }^{2}$ A survey of the literature identifies those theoreticians who have contributed most significantly and cogently to the issues of adult growth are Jung, Erikson, Neugarten, Levinson, and Sheehy.

For the purpose of this study, the term developmental psychology will refer to the mental and behavioral characteristics associated with the gradual unfolding through successive stages of human growth and evolution. These successive changes or developmental stages are characterized by specific issues or problems which must be addressed, if not mastered, before proceeding to subsequent stages (Jacobi, 1967; Erikson, 1950; Levinson in Neugarten, 1968; Sheehy, 1974). Only when these tasks are successfully mastered, can the 
individual devote their full energy toward future growth. This passage between stages can be described as a turning point: "...a crucial period of increased vulnerability and heightened potential." 3

THEORIES OF ADULT DEVELOPMENT

Understanding human life as a developmental process is an integral and basic component of many psychologies. Historically, theoreticians have devoted most attention to those most visable changes occurring between birth and adolescence and have not specifically addressed those changes that occur throughout adult life.

of those who view development as a dynamic process continuing throughout the life span, Carl Jung emerges as one of the earliest and clearest exponents of this concept. His teachings, which stress the importance of addressing differing life tasks at different stages of life can be viewed as the foundation of life-span psychology (Jung, 1933) .

Jung likens the life cycle to the course of the sun, in which the first half is concerned with the expansion of psychic energies and entrenchment in the social realm and world of external reality. In contrast, the second half of life focuses on contraction of these creative energies into the inner illumination of the self (Jung, 1933).

Generally speaking one can say that whereas the first half of life is, in the nature of things, governed and determined by expansion and adaptation to outer reality, the second half is governed by 
restriction or reduction to the essential, by adaptation to the inner reality. 4

Those tasks relevant to the first half of life involve broadening and consolidating physical existence, striking roots in the world, and concern with achievement and usefulness in the external reality. In contrast, the tasks of middle age involve an acceptance of one's own mortality, a turning inward of energy in preparation for death, and understanding of the meaning of one's individual life.

To confront this goal (death) with the full force of the capacities for growth imminent in the psyche constitutes the real meaning of the second half of life and the highest dignity of $\operatorname{man} .5$

The transition from youth to middle age occurs around 35 to 40 years of age and constitution a time of crisis. The more successfully an individual has been engaged in the external world, the more reluctant they are to relinquish the known ideals and principles of youth to embrace those of middle age. 6

The worst of it all is that intelligent and cultivated people live their lives without even knowing of the possibility of such transformation...thoroughly unprepared we take the step into the afternoon of life; worse still, we take this step with the false assumption that our truths and ideals will serve us hitherto. But we cannot live the afternoon of life according to the programme of life's morning; for what was great in the morning will be little at evening, and what in the morning was true will at evening have become a lie.?

According to Jung, this mid-life transition may also present a crisis in the marriage. In accepting the inevitability of death, each partner strives to complete the 
wholeness of their life and may choose to develop those aspects of themselves which previously were left unattended. These changes often result in pressure to the relationship, as well as to the individual.

The concepts developed by Erik Frikson have also contributed greatly to viewing development as an ongoing process continuing throughout life. Erikson conceives of psychosocial development as proceeding through a series of critical steps based on specific issues which are brought into focus at different stages of life. The first five (5) stages of development are concerned with the period of birth through adolescence and focus on the issues of trust, autonomy, initiative, industry, and identity (Erikson, 1950). When these issues have been resolved the individual enters adulthood with a firm sense of identity. Intimacy constitutes the basic issue of young adulthood and the tasks involving making concrete affiliations and partnerships and developing the ethical strength to stand by commitments even though this may involve sacrifice. Unsuccessful resolution of this issue is manifested in isolation of the self, avoidance of contact, and orgasmic difficulties (Erikson, 1950).

Erikson identifies the central issue in the following stage in the life sequence as being generativity, a "concern in establishing and guiding the next generation." 8 This concept is not specifically limited to childbearing, but is expanded to include productivity and creativity in contribution to future generations. If generativity fails to 
develop the individual experiences a sense of stagnation (Erikson, 1950).

The final stage in Erikson's life sequence is characterized by a concern with ego integrity...

...acceptance of one's one and only life cycle as something that had to be and that by necessity permitted no substitutions...9

When ego identity is not achieved, the individual frequently experiences despair and fear of death.

Bernice Neugarten is a third exponent of on-going adult development and describes expected age-specific behaviors. In her 1950's study of 332 Kansas City residents between the ages of 40 and 90 she found progressive direction of energy toward inner rather than outer stimuli (Neugarten, 1968). Characteristic attitudes and behaviors associated with aging include a limited sense of time, increased importance of reflection and stocktaking, the value of wisdom over social power, and a change from active to passive mastery of environment. 10 Unlike Jung and Erikson, Neugarten places great emphasis on the physiological demands of aging which require more ego energy to be channeled inward, leaving less energy available to the external world.

Levinson (in Neugarten, 1968) also identifies specific developmental stages of adulthood. These are "Leaving the Family," "Getting into the Adult World," "Settling Down," "Becoming One's Own Man," "Mid-Life Transition," and "Restabilization."11 Like Jung, Erikson, and Neugarten, this framework embraces the general view of expansion and 
investment in the outer world in the first half of life, followed by a crisis at mid-life during which the issue of mortality is personally addressed, and a subsequent re-direction of energies to inner processes during the second half of life. Although Levinson's concepts appear to be applicable to all adult development, it is important to note that the sample used for this research consisted entirely of men.

Most recently, Gail Sheehy has popularized the concept of "predictable crises of adult life" (Sheehy, 1974). Her rationale for anticipating life crises is that this knowledge provides a framework for understanding problems-in-living as stages in growth rather than evidence of personal inadequacy or caused by others. This study involved interviews with 115 women and men aged 18-55. Although the sample for this study is limited to middle class urban subjects, it provides a detailed description of the problems likely to be encountered by this population throughout adult life.

Sheehy's findings suggest that age-specific developmental tasks do exist throughout adult life. These life tasks were presented within the framework of the following decades: "Pulling Up Roots" (late adolescence), "The Trying Twenties," "Catch - 30," and "The Age 40 Crucible." The ontogenetic tasks specifically related to the "Pulling Up Roots" stage involve establishing physical and emotional separation from parents. This is often manifested in hostility to the family and other traditional institutions, and in a negative view of one's own self. The basic issue of 
"The Trying Twenties" involves taking hold in the adult world, with a corresponding focus in the external world. Tasks include establishing a life work, establishing an intimate relationship, and finding a mentor. 12 The "Catch 30" period involves a re-evaluation of earlier life decisions. This review may result in basic changes in life style, marriage and/or job. For example, the woman who focused on family life in her $20^{\prime} \mathrm{s}$ may at this time reevaluate her desire for a career. As in other transition times, this period involves heightened vulnerability and increased internal turmoil. Toward the middle of this decade, mid-life issues arise. These include confrontation with one's own mortality, a change in sense of time, and rethinking of previous religious and moral beliefs. The final stage described in this study is "The Age 40 Crucible." The tasks involve operationalizing the changes made in preparation for the second half of life. Men and women in this study experienced a tendency to expand roles by focusing on those behaviors that had been traditionally associated with the opposite sex. For example, many women at this age became active in politics or business. Such role reversals often resulted in marital and/or sexual discord. ${ }^{13}$

A second research study of developmental tasks of adult life was conducted by Roger Gould, M.D. (1972). Gould completed an observational study of seven age-homogeneous groups of clients at UCLA Psychiatric Out-Patient Clinic. Repetitive themes were extracted from each group. Substantial 
similarity was found within groups, and differences between groups. He then utilized these themes in creating a questionnaire which was administered to 524 white, middle-class, educated men and women from a non-client population. Results suggested that both populations had similar, age-specific concerns. ${ }^{14}$ For example, the 22-28 year old group indicated concern with autonomy, separateness from the family, and spent much of their energy mastering what they felt they "ought to do," i.e. finding success in a job, with intimate relationships, and generally establishing themselves in the adult world. The 35-43 year old group showed agreement on issues relating to increased awareness of limited time, inward questioning of self and life goals, and a change in relationship to one's own aging parents who now look more to their children for increased support.

A third research study done in this area was conducted by Neugarten and Rosen (1964). In this study, 144 persons aged 40-71 who were equally represented in age, sex, and social class were administered a Thematic Apperception Test (TAT) to test the hypothesis that with increased aging, there occurs a decrease in energy available for dealing with stimuli from the outer world. The hypotheses were that older persons are less likely to: 1) introduce characters; 2) involve inner and intra-personal conflict; 3) interpret characters as engaged in vigorous, assertive activities; and $4)$ elaborate on affect and feeling states. These criterion were utilized to measure outward-directed energy. The 
findings suggested that older persons are: 1) less able to integrate wide ranges of stimuli; 2) less able to perceive and deal with complicated or conflictual situations; 3 ) tend less often to perceive affect as an important part of life; and 4) tend toward inactivity or passivity rather than more active, assertive forms of behavior. ${ }^{15}$

In summary, each of the theories and research studies outlined above witnesses a common theme in the onotgenetic adult development. The first half of life is a time of general expanding and involvement in the external, social world with corresponding tasks that often include finding a life work, striking roots in the world, concern with the physical existence, achievement, and establishing intimacy and affiliations with others. Around the ages of 35-40, a mid-life transition or crisis is likely to occur. The central issue is the personal confrontation with one's own mortality and a subsequent re-definition of goals and values. Regret, despair, isolation,.. and fear of death often result when these issues are not resolved. When the individual successfully accepts the limits of their own existence, the second half of life is characterized by an inward re-direction of energies toward the self, a re-stabilization and sense of renewal, and an understanding and acceptance of the meaning of one's own life. 
CHAPTER III

RESEARCH DESIGN AND METHODOLOGY

INTRODUCTION

This descriptive study employed the Mooney Problem Checklist in order to elicit and categorize the range of problems-in-living experienced by women presenting themselves for out-patient mental health treatment.

\section{CLIENT POPULATION}

The client population consisted of women aged 20-29 and 40-49 who came to mental health agencies requesting outpatient counseling services.

\section{INSTRUMENT}

The Mooney Problem Checklist (see Appendix) was selected as most appropriate to the needs of this study. This instrument was developed as a simple means to communicate personal problems between client and counselor. The Checklist is a series of 288 problem statements grouped into nine problem areas. The procedure for completion is simple. Clients read through the checklist and underline the problems which are of concern to them, circle the ones of most concern, and write a summary in their own words. The areas, 
with the number of items in each, are listed below:

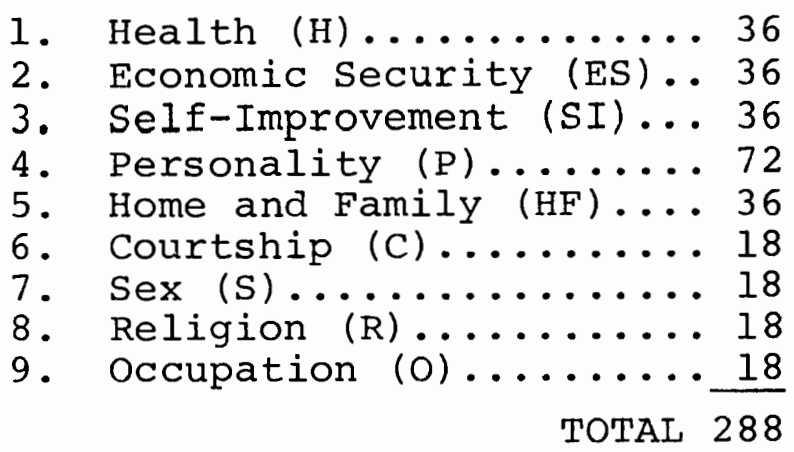

The problems on the Checklist were developed from surveys, suggestions from clinicians, and a literature review. The present Mooney Problem Checklist represents the third revision, and is printed in a six page folder in a way that provides for ease of response. The average completion time is 20-30 minutes.

Identifying information requested on the cover of the Checklist includes name, date, occupation, age, sex, marital status, and number of children. To insure confidentiality in this study, clients were instructed by the face sheet to omit their name. This item was also crossed off the Checklist. An additional item, "Gross Household Income," was included with the identifying data. This item was divided into six income brackets ranging from $\$ 0$ to $\$ 16,000$ and above, and clients were asked to circle the appropriate category. An aim of this study was to investigate and describe the relationship, if any, between these variables and the expressed concerns of women. 
This instrument was selected for many reasons. Primarily, the checklist covers a wide range of problem areas including interpersonal, environmental, and situational. In addition, it has been demonstrated to be an effective tool in research to express the major concerns of identified groups, and to indicate changes and differences in problem areas in relation to age, sex, occupation, marital, and socio-economic status.

The Checklist is brief, self-administering, and easily understood by persons of differing educational backgrounds. It is not linked with a specific treatment modality, and has been demonstrated to be helpful for both clients and counselors. Clients are provided with an opportunity to review and summarize their concerns, and to therefore prepare for the interview. Insights may be gained in this process. Benefits to the counselor include a time-saving review of the client's problem areas, and an indication of the client's willingness to discuss specific problem areas. Insights may be gained from their interrelationship.

One of the potential limitations of the checklist is that it lacks reliability. The research design controlled for reliability by administering the instrument in a specific and consistent time sequence. The Checklist has also been described as non-normative and not a depth technique. For the purpose of this research, neither norms nor projective data were desired and therefore did not prove to be limitations. 
TIMING

Two factors were considered in regards to timing for this study: 1) at what time during the intake process the individual would complete the Checklist, and 2) the period of time over which the data would be collected. In order to maintain sensitivity to the issue of reliability, the instrument was administered at a uniform time during the intake process. The Checklist was consistently given to clients at the beginning of the intake process before any professional intervention. Research in this area indicates that clients' perception of their problems change after contact with identified "helper." An essential aim of this research was to capture women's definitions of their problems as purely as possible, before professional interpretation.

In order to provide a sample which was both representative of the client population and adequate in size, data was collected over a six week period of time during the months of January and February 1978.

\section{SETTING}

In order to obtain data which was representative of women seeking out-patient mental health services in the Portland metropolitan area, negotiations were begun in October 1977 with eight public and private agencies. By January 1978, contracts were arranged with two service providers. of those choosing not to participate, the major objection 
came from agencies who saw themselves as beseiged by large client populations coupled with limited staff; in addition, two clinics were involved in program restructuring and were therefore unwilling to channel program energy to research at this time. Another objection came from agencies that viewed the Checklist as an additional step, although voluntary, between request and delivery of services rather than as a useful pre-treatment tool.

The two service provides involved in this study include one public agency administered directly by the county, and one private agency operating with a county contract. These agencies are Clackamas County Mental Health Center, Marylhurst Campus; and Tualatin Valley Mental Health Center in Washington County.

\section{PROCEDURE}

After first obtaining the co-operation of the administrative staff of these agencies, the researchers met with the clinical and clerical staffs to arrange for a method of data collection that would be least obtrusive to existing program operation, and sensitive to the needs of the client. A face sheet was attached to the Checklist which explained the research project to the clients, and provided directions for completing the Checklist, thus ensuring that the instrument was self-administering and would require minimal staff involvement. Additional salient features included in the 
face sheet were statements stressing the confidentiality and voluntary nature of participation (see Appendix). Clients were also given the option of having a copy provided to their therapist at the researcher's expense. In return for agency involvement, provisions were made for the clinics to receive outcome data relevant to their program.

As a result of the negotiations with clinic staffs, the following data collection procedures were developed. At Clackamas County Mental Health Center therapists schedule their own appointments and therefore introduced the study to clients during their initial telephone contact. At their request, a brief description of the study and client involvement was provided in writing for this purpose. Women who chose to participate were asked to come 30 minutes earlier than usual to complete the Checklist. It was stressed that receipt of services was not contingent on participation. Clerical staff received the completed Checklist and, at the client's request, made copies for the therapist.

At Tualatin Valley Mental Health Center, all adult women clients were routinely asked to arrive 45 minutes before the scheduled interview. Previous agency procedure required clients to arrive 30 minutes early. Upon arrival, the women received the Checklist in addition to required intake forms. The face sheet was relied on to convey the voluntary nature of participation. Collection procedures were similar to Clackamas County in that clerical staff received the completed Checklist and provided copies at the 
client's request. Weekly personal contact was maintained with both clinics throughout the data collection period to address problems and answer questions that might arise. 
CHAPTER IV

FINDINGS

INTRODUCTION

A descriptive summary of the research results follows. The findings will be organized in two categories designated as description of sample and data results.

\section{DESCRIPTION OF SAMPLE}

Data collection occurred over a six week period of time at both agencies. At Tualatin Valley Mental Health Center (T.V.M.H.C.) this period of time extended from January 10 to February 17, 1978; and at Clackamas County Mental Health Center from January 16 to February 24, 1978. Due to an overload of service requests at T.V.M.H.C. during this time, intake was reduced, and clients were placed on a waiting list and seen as therapy time became available.

During the time of data collection at T.V.M.H.C., 30 women in the 20-29 age category and 5 women in the 40-49 age category were seen at the clinic. Of these, the sample obtained includes 30 women in their $20^{\prime} \mathrm{s}$ and 4 women in their $40^{\prime} \mathrm{s}$ who agreed to participate in this research study. At Clackamas County, 13 women in the 20-29 age category and 2 women in the 40-49 age category were seen for an intake 
interview. No (0) responses were obtained from this clinic. Periodic checks with clinic personnel yielded no completed checklists and no explanation for this lack of participation was given. Tables I through IV provide a descriptive profile of the women in the sample. These delineate the variables of income, marital and employment status, and number of children.

\section{TABLE I}

DESCRIPTION OF INCOME DISTRIBUTION

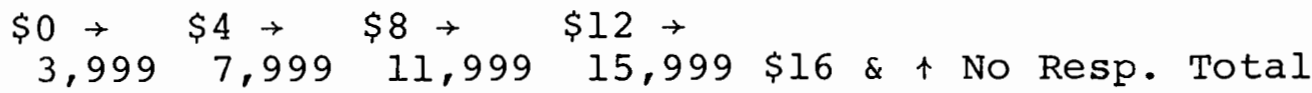

\begin{tabular}{ccccccccc}
$20^{\prime} \mathrm{s}$ & 12 & 3 & 4 & 4 & 2 & 5 & 30 \\
\hline $40^{\prime} \mathrm{s}$ & 1 & 1 & 0 & 1 & 0 & 1 & 4 \\
\hline \hline Total & 13 & 4 & 4 & 5 & 2 & 6 & 34
\end{tabular}

TABLE II

DESCRIPTION OF MARITAL STATUS

Single Married Divorced/Separated Other* Total

\begin{tabular}{cccccc}
20 's & 12 & 9 & 8 & 1 & 30 \\
\hline 40 's & 0 & 2 & 2 & 0 & 4 \\
\hline \hline Total & 12 & 11 & 10 & 1 & 34
\end{tabular}

*includes "non-legal situation" 
TABLE III

DESCRIPTION OF EMPLOYMENT STATUS

Employed* Unemployed No Response Total

\begin{tabular}{ccccc}
20 s & 17 & 12 & 1 & 30 \\
\hline 40 's & 1 & 3 & 0 & 4 \\
\hline \hline Total & 18 & 15 & 1 & 34
\end{tabular}

*includes salaried positions

TABLE IV

DESCRIPTION OF NUMBER OF CHILDREN

$\begin{array}{llllllll}0 & 1 & 2 & 3 & 4 & 5 & \text { No Response Total }\end{array}$

\begin{tabular}{ccccccccc}
20 's & 16 & 9 & 2 & 3 & 0 & 0 & 0 & 30 \\
\hline 40 's & 0 & 0 & 0 & 1 & 1 & 1 & 1 & 4 \\
\hline \hline Total & 16 & 9 & 2 & 4 & 1 & 1 & 1 & 34
\end{tabular}

When the data is analyzed the following profile emerges as representative of each age category. The average client in the 20-29 year old category has a mean age of 24.3 years, is single, has 0.7 children, and is employed with an income of $\$ 5,800$ per year. Acknowledging the limitations of the small sample, $(\mathrm{N}=4)$, an average description of the 40-49 year old category is characterized as a woman with a mean age of 43.2 years, who is equally as likely to be married as to be divorced or separated, has 4 children, is unemployed with an income of $\$ 7,333$. 
DATA RESULTS

Results will be presented in numerative and narrative format. Due to the fact that the problem areas were unequally represented in number, the response scores have been converted through the use of a common denominator in order to enable comparison. The denominator chosen was 72 , since this number represents the largest single category on the Checklist. Therefore, in each category, the total possible response is 72. A score of 20.9, for example, would indicate that in this sample, the mean response was 20.9 items out of the possible 72. As outlined in the Methodology, both total and circled responses will be presented in the 9 problem areas: Health (H), Economic Security (ES), Social Improvement (SI), Personality (P), Home and Family (HF), Courtship (C), Sex (S), Religion (R), and Occupation (O).

From Table V, it can be seen that of those items underlined as being of a concern to the participants, the area of Personality yielded the largest mean number of total responses (22.2). The area of Social Improvement registered only slightly fewer responses (20.9). Following this in decreasing order of total responses are: Economic Security (12.9), Home and Family (12.7), Courtship (11.7), Occupation (10.0), Health (9.7), Religion (8.0), and Sex (3.9).

of the circled items (those indicating most concern, the priorities are as follows: Personality (8.4), Social Improvement (6.5), Courtship (6.3), Home and Family (5.4), 
TABLE V

MEAN NUMBER OF TOTAL AND CIRCLED RESPONSES ACCORDING TO PROBLEM AREA FOR 20 - 29 YEAR OLD WOMEN

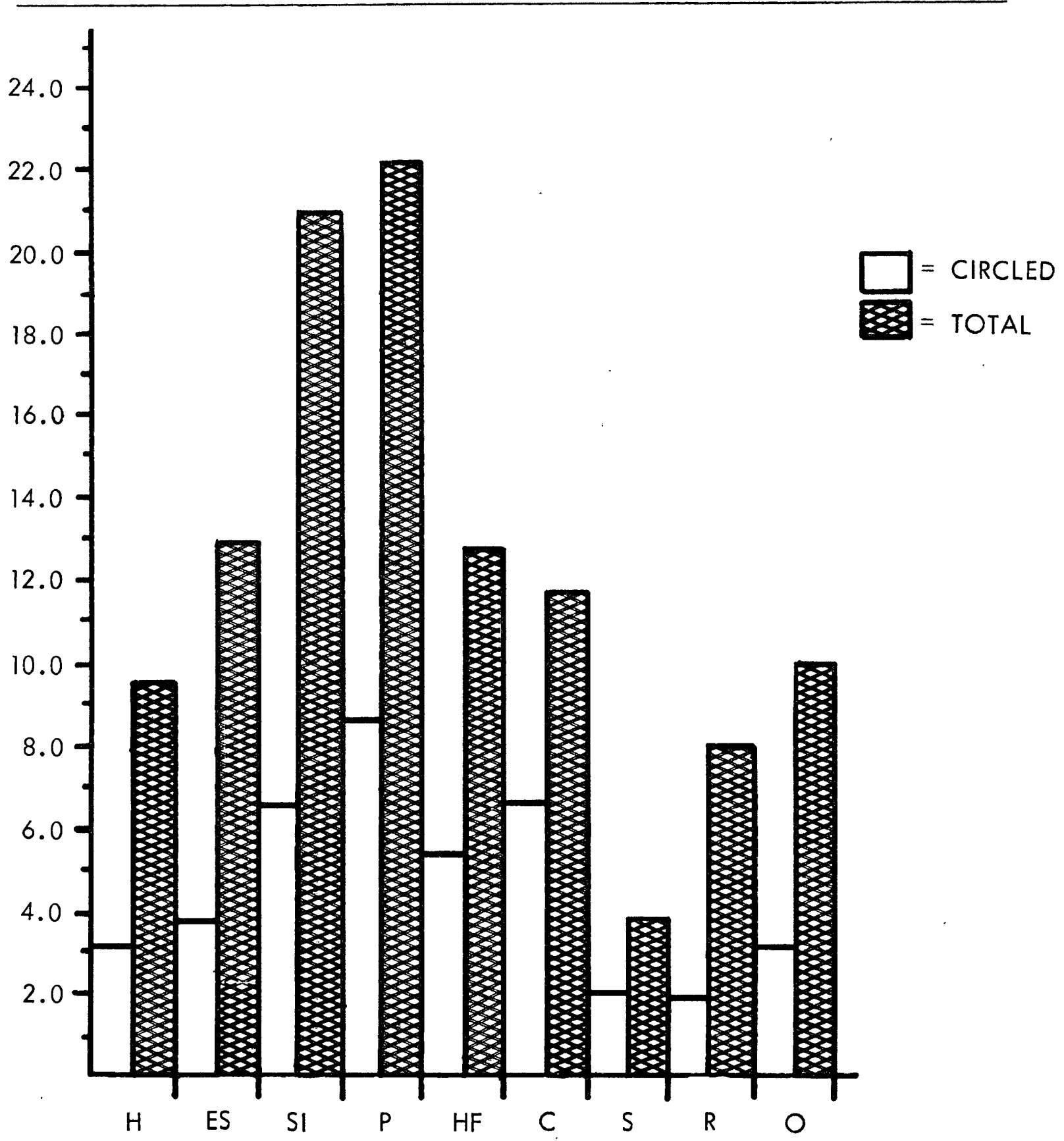

Mean number of total responses $=52.9$

Mean number of circled responses $=20.1$ 
Economic Security (3.9), Occupation and Health (3.2 each), Sex (2.0), and Religion (1.9).

For this 20-29 year old group, the overall percentage. representing the number of items circled as being of most concern to total underlined items is $38.0 \%$. The following chart delineates this percentage according to problem area:

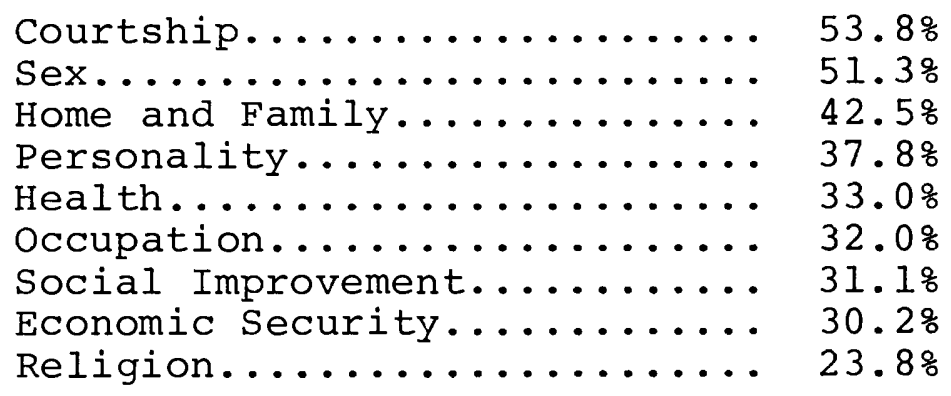

The following data summarizes the results for the 40-49 year old age group. It is important to remember that this sample includes only 4 women and that interpretation or generalization is severely limited.

Table VI shows that of those items underlined as being a concern to the participants, the area of Personality produced the largest mean number of total responses (23.2). In descending order, the remaining categories are: Social. Improvement (20.5), Health (16.0), Home and Family (14.0), Economic Security (11.0), Religion (9.0), Courtship (8.0), Sex $(5.0)$, and Occupation (1.0).

The distribution of mean number of circled items for this age group is as follows: Personality (16.5), Home and Family (9.5), Social Improvement (7.5), Health (6.0), Religion (5.0), Courtship and $\operatorname{sex}(4.0$ each), Economic 
MEAN NUMBER OF TOTAL AND CIRCLED RESPONSES ACCORDING TO PROBLEM AREA FOR 40 - 49 YEAR OLD WOMEN

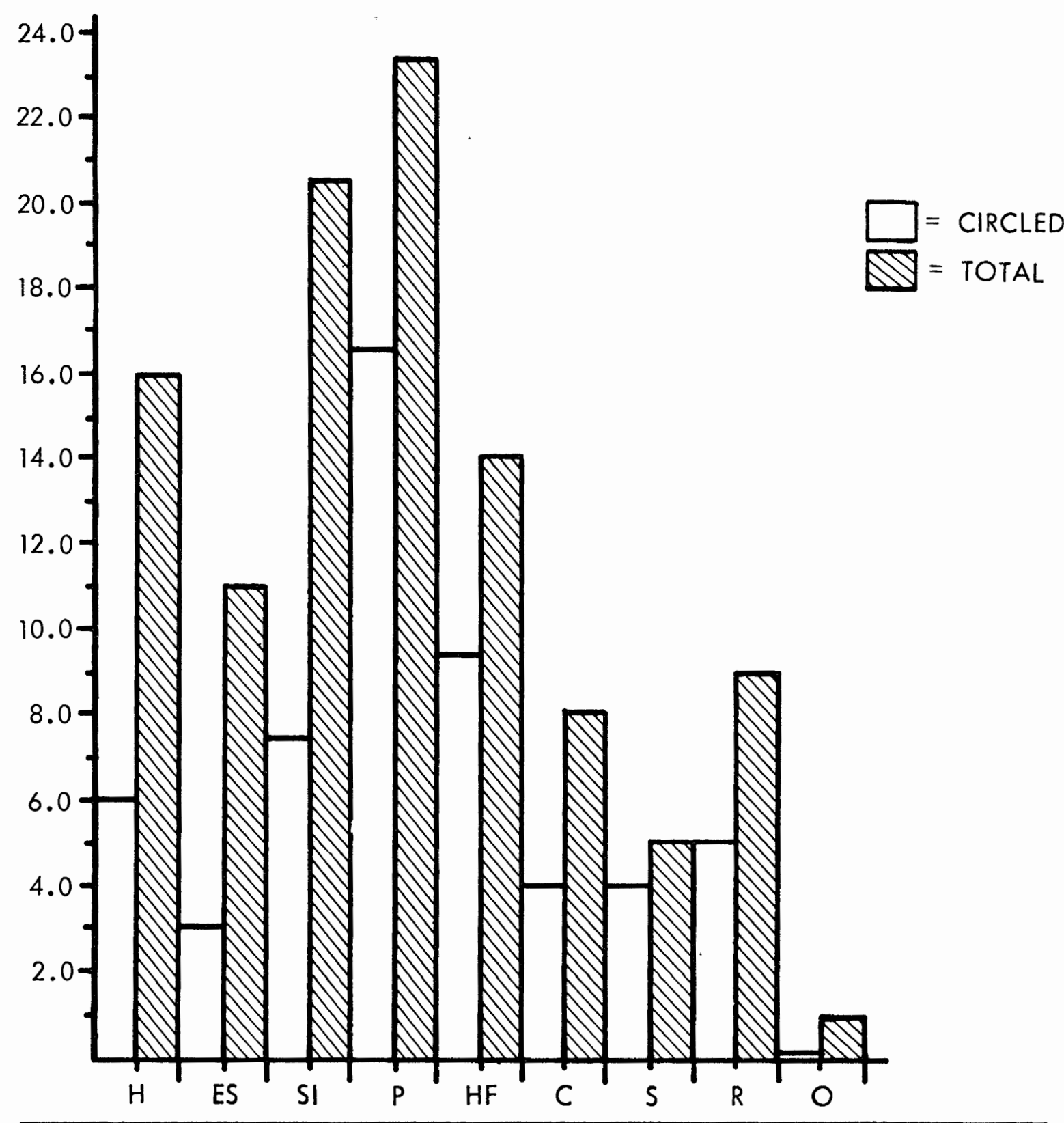

Mean number of total responses $=59.8$

Mean number of circled responses $=32.8$ 
Security (3.0), and Occupation (0).

The overall percentage of circled to total items is 54.8\%. The following itemizes this percentage by problem area :

Sex

Personality

Home and Family

Religion

Courtship

Health

Social Improvement

Economic Security

Occupation
$80.0 \%$

$71.1 \%$

$67.9 \%$

$55.6 \%$

50.08

37.58

$36.6 \%$

27.38

$0 \%$

OTHER VARIABLES

In order to investigate the influence of specific variables on problem area, age distinction was ignored, and data was differentiated by income, marital status, employment status, and number of children.

\section{Income}

The raw data presented with income as the dependent variable is provided in Appendix B. The 5 distinct categories have been collapsed into 3 categories to achieve a more balanced dispersion. The categories are: $\$ 0-3,999$ $(\mathrm{N}=13) ; \$ 4,000-11,999(\mathrm{~N}=8) ;$ and $\$ 12,000$ and above $(\mathrm{N}=7)$. Six respondents did not provide income information and were grouped in a category entitled 'no response.'

Following is a listing for each income category of the 4 problem areas containing the largest number of total 
then circled items and the 2 problem areas containing the least number of total and circled items.

\section{TABLE VII}

HIGHEST AND LOWEST MEAN NUMBER OF TOTAL AND

CIRCLED RESPONSES ACCORDING TO PROBLEM AREA AND INCOME

$\$ 0 \quad 3,999$

Mean Number of Total Responses
$(\mathrm{N}=13)$

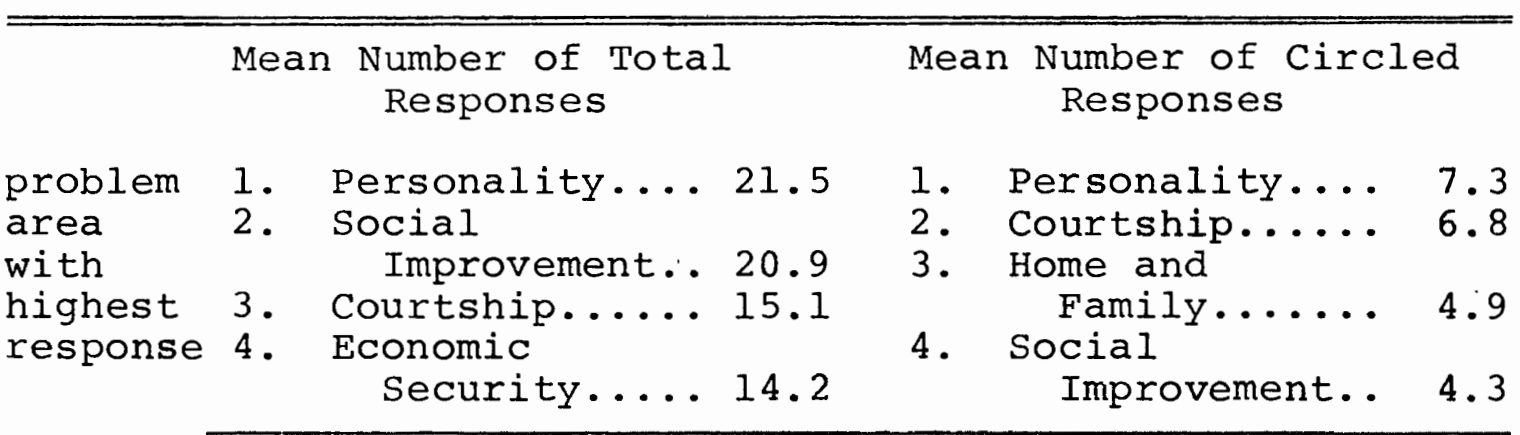

problem

area

with

lowest

1. Sex........ 3.4 1. Religion...... 1:5 response

2. Religion..... 7.1 2. Occupation.... 1.8

$\$ 4,000 \quad 11,999$

$(\mathrm{N}=8)$

Mean Number of Total Responses
Mean Number of Circled Responses

problem 1. Personality... 25.9 1. Personality.... 10.9 area 2. Social

with Improvement.. 24.8

2. Social

highest 3. Occupation..... 15.5

response 4. Economic

Security..... 13.0

Improvement.. 10.0

3. Occupation.... 7.0

4. Courtship..... 5.5

problem

area

with

1. Sex........ 5.5

1. Religion...... 1.0

lowest

2. Religion...... 9.5

2 .

Sex........ 2.0

response 
TABLE VII (cont'd)

$\$ 12,000$ above $\quad(\mathrm{N}=7)$

Mean Number of Total Responses
Mean Number of Circled Responses

problem 1. Personality.... 21.0 1. Personality.... 10.9 area 2. Social

2. Home and

with Improvement.. 19.1

highest 3. Home and

response Family...... 15.1

4. Religion...... 10.4

Family..... 8.3

3. Social

Improvement. . 6.6

4. Courtship..... 5.1

problem

area

with

lowest

1. Courtship..... 4.6 1. Occupation.... 1.1

2. Sex........ 4.6 2. Sex........ 2.9 response

Marital Status

The raw data compiled on problem area using marital status as the dependent variable is presented in Appendix C. The groupings of single, married, and divorced/separated are well represented in this sample with N's of 12,11 , and 10 respectively. One participant listing her marital status as "non-legal situation" was placed in a separate category entitled 'other.'

Following is a listing for each category of the 4 problem areas containing the largest number of total then circled items and the 2 problem areas containing the least number of total and circled items. 


\section{TABLE VIII}

\section{HIGHEST AND LOWEST MEAN NUMBER OF TOTAL AND \\ CIRCLED RESPONSES ACCORDING TO PROBLEM \\ AREA AND MARITAL STATUS}

Single Women

Mean Number of Total
Responses

Mean Number of Circled
Responses

problem 1. Social

1. Personality.... 5.6

area

Improvement.. 19.3

with

2. Personality.... 18.0

highest 3 . Economic

response

Security.... 14.8

4. Occupation..... 13.0

2. Courtship..... 4.3

3. Economic

4. Social

security.... 3.2

Improvement.. 3.0

problem

area

with

lowest

1. Sex......... 2. 0

1. $\operatorname{sex} \ldots . . . . . . .1 .0$

response

2. Religion...... 5.3

2. Religion.

1.3

\section{response}

Married Women
Mean Number of Total Responses
Mean Number of Circled Responses

problem 1. Personality...2 20.2 1. Home and

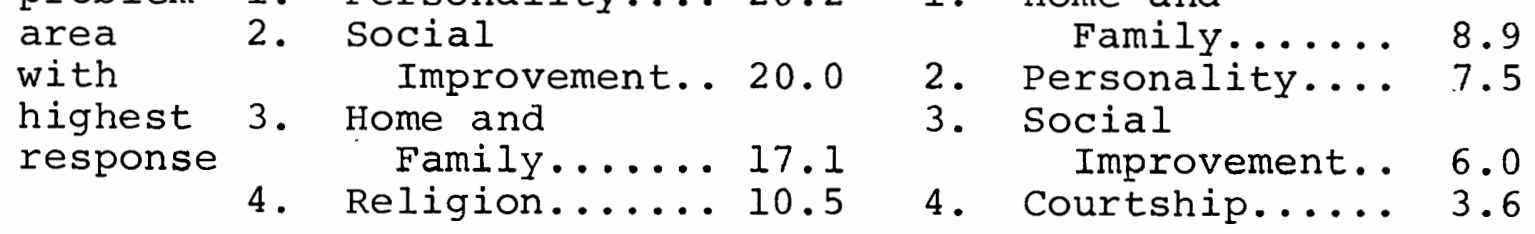

problem

area

1. Courtship..... 5.5

1. Occupation.... 0.0

with

2. Sex......... 5.5

2. Sex......... 2.. 2

lowest

Occupation.... 5.5

response 
TABLE VIII (cont'd)

Separated/Divorced Women

Mean Number of Total Responses problem 1. Personality.... 29.4 area

with

2. Social

highest 3. Courtship..... 17.6 response 4. Home and

Family...... 14.4
Mean Number of Circled

Mean Number of Circled
Responses
1. Personality.... 15.1

2. Social

Improvement.. 11.4

3. Courtship..... 10.0

4. Occupation.... 6.4

problem

area

with

1. Sex........ 4 .

$4.4 \quad 1$.

Religion...... 2.4

lowest

2. Religion.......

8.0

2 .

Sex.

3.2 response

When problem areas were combined, the separated/Divorced group of women underlined more problem statements $($ mean=70.0) than Married (mean=54.9) and Single (mean=5l.8) women. The Separated/Divorced group also circled more items $($ mean=34.2) as especially problematic than either Married (mean=21.0) or Single (mean=13.3) women. The ratio of circled to total underlined items was also highest for this category (48.9\%) with Married women (38.3\%) and Single women (25.7\%) following. Conversely, single women indicated the fewest total and circled concerns and had the smallest ratio of circled to total responses.

\section{Employment status}

The data collected in response to the question regarding the variable of employment status is provided in Appendix D. This includes respondents in 3 categories: Employed 
$(\mathrm{N}=18)$; Unemployed $(\mathrm{N}=15)$; and No Response $(\mathrm{N}=1)$. As defined earlier, the category of "Employed" designates those women who are receiving a salary.

The following lists the 4 problem areas containing the largest number of total and circled responses, and the 2 problem areas containing the least number of total and circled responses for the categories of "Employed" and "Unemployed." The 1 participant who did not respond to this item is not included in this listing.

When all problem areas were combined, the Unemployed group underlined more problem statements (mean=61.3) than the Employed group (mean=54.8). The Unemployed women also circled more statements (mean=25.6) as of particular concern than did the Employed women (mean=19.7). The ratio of circled to total items is also higher for the Unemployed group (41.8\%) than for the women who were employed (35.9\%). It is of interest to note that the Unemployed group underlined and circled more problem statements than their counterparts in all problem areas except Courtship and Occupation. 
TABLE IX

HIGHEST AND LOWEST MEAN NUMBER OF TOTAL AND CIRCLED RESPONSES ACCORDING TO PROBLEM AREA AND EMPLOYMENT STATUS

Employed

Mean Number of Total Responses
Mean Number of Circled Responses problem 1. Personality.... 21.0 area

with

2. Social

Improvement. . 19.4

highest 3. Courtship..... 12.9 response 4. Economic

Security.... 12.1
1. Personality.... 8.4

2. Courtship..... 7.1

3. Social

Improvement. . 6.2

4. Home and

Family...... 4.6

problem

area

with

lowest

1. Sex........ 3.3

1. Religion...... 1.1

response

2. Religion...... 7.8

2 .

Sex......... 1.5

Unemployed

Mean Number of Total Responses
Mean Number of Circled Responses problem 1. Personality.... 22.9

area

with

highest
2. Social

Improvement. . 22.8

3. Home and

Family..... 14.8

4. Economic

Security..... 13.3
1. Personality.... 10.1

2. Home and

Family..... 7.2

3. Social

Improvement. . 6.7

4. Economic

Security.... 5.3

problem

area

with

lowest

1. Sex........ 4.8

1. Occupation..... 1.3

2. Occupation.... 5.1

2 .

3.2

response

Number of Children

Appendix E provides a summarization of the data from the viewpoint of the variable involving parental status. This includes women responding in 7 distinct categories: 
Those with no (0) children, $(\mathrm{N}=16)$; with 1 child, (N=9); with 2 children, $(\mathrm{N}=2)$; with 3 children, $(\mathrm{N}=4)$; with 4 children, $(\mathrm{N}=1)$; with 5 children, $(\mathrm{N}=1)$; and 'no response,' (N= 1). The data results collected from women who indicated they had more than one child must be viewed as extremely biased due to the small sample sizes and will not be included in this portion of the text. The following listing will therefore deal only with the groups indicating either no (0) or 1 child. Extracted from the raw data are the 4 problem areas containing the largest number of total and circled responses, and the 2 problem areas containing the least number of total and circled responses.

TABLE X

HIGHEST AND LOWEST MEAN NUMBER OF TOTAL AND CIRCLED RESPONSES ACCORDING TO PROBLEM AREA AND NUMBER OF CHILDREN

No (0) Children

Mean Number of Total Responses

problem 1. Social area with Improvement. . 23.8 Personality.... 22.1 highest 3. Occupation.... 15.8 response 4. Economic

Security..... 14.4
Mean Number of Circled Responses

1. Personality.... 9.4

2. Social

Improvement. . 8.1

3. Courtship..... 7.0

4. Home and

Family...... 6.1

problem

area with lowest 1. Sex........ 3.8 1. Religion...... 1.8 response

2. Sex........... 2.0 
TABLE $x$ (cont'd)

One (I) Child

Mean Number of Total

Responses

Mean Number of Circled Responses

problem 1. Personality... 23.8 1. Personality.... 8.1 area 2. Social

with

Improvement. . 19.7

highest 3. Courtship..... 12.9

response 4. Home and

Family...... 10.9

2. Courtship..... 6.2

3. Social

Improvement.. 4.6

4. Economic

Security.... 3.7

problem

area

with

1. Sex........ 2.2

1. Sex........ 1.8

lowest

2. Occupation.... 4.4

2. Religion...... 2.2 response

3. Occupation.... 2.2 


\section{CHAPTER V}

\section{CONCLUSIONS AND RECOMMENDATIONS}

\section{INTRODUCTION}

The purpose of this research study was to investigate whether age-specific developmental issues existed within a selected sample of women in distinct age groupings who were seeking outpatient mental health counseling. The intention to describe concerns specific to the decades of the 20 's and $40^{\prime} \mathrm{s}$ and to compare potential differences was severely restricted by the extremely small sample obtained from women in their $40^{\prime} \mathrm{s}$. This small sample can be attributed to the fact that data was collected from only one of the two contracting agencies, that in the participating agency intake was reduced during the data collection period, and that women in this age group represented only a small proportion of those requesting mental health services at this time.

Therefore, the conclusions of this study will focus on describing concerns commonly expressed by women in their $20^{\prime}$ s and relating these to developmental issues predicted in a review of the literature. In addition, this section will examine the influence of the variables of income, marital status, employment status, and number of children on problem areas. 
Finally, recommendations for further research and application of these findings will be presented.

\section{CONCLUSIONS}

A review of the literature and research in the area of adult development describes common tasks for people in their 20 's as including finding a lifework, striking roots in the world, concern with physical existence and achievement, and establishing intimacy and affiliation with others. In relation to those problem areas presented in the Mooney Problem Checklist, the researchers anticipated a correspondingly higher response rate in the areas of Courtship, Home and Family, Sex, Economic Security, and Occupation. These areas were thought to indicate the general focal themes of expansion and involvement in the external world. Conversely, a lower rate of response was anticipated in the areas of Health, Religion, and Personality, which were thought to reflect a more introspective focus. A review of the statements comprising the category of Social Improvement failed to distinctly characterize this category as specifically representing either external or internal focus.

In discussing the conclusions, the three descriptive data measurement's presented in the findings will be utilized. These are:

1. Mean number of total underlined items

2. Mean number of total circled items, and

3. The percentage of circled to underlined items. 
Total underlined items refers to all problem statements underlined and thereby indicated as problematic. Total circled items refers to those problem statements identified as being of specific concern. Finally, the percentage of circled to underlined items refers to the relationship between the two.

Age

For the thirty women sampled who were in their 20 's, problems relating to Courtship ranked highest of all problem areas when measuring the percentage of circled to underlined items. This percentage indicates that over half (53.8\%) of all items underlined were designated as of critical concern. In addition, the area of Courtship ranked third highest when measuring circled items. These findings are consistent with the literature which identifies establishing intimacy in relationships as a crucial task of young adulthood (Erikson, 1950; Gould, 1972; and Sheehy, 1974).

As anticipated, problems relating to Home and Family were found to be of high concern in this age group. This category ranked third in the percentage measurement (42.5\%). Issues of Home and Family scored fourth highest of the nine categories in both circled and underlined items.

Although items relating to sex were expressed as being of little concern in both underlined and circled tabulations, the percentage was high $(51.3 \%)$ indicating that when sexual issues are of concern they are likely to be of critical concern. 
Response rate in the category of Economic Security was lower than anticipated. While this category ranked third highest when measuring underlined items, it ranked fifth in circled items and eighth when measuring the percentage between the two.

Although Gould (1972) and Sheehy (1974) found that job mastery was an important concern in this age group, items relating to occupation were not identified in this study as one of the top five concerns when measuring either underlined responses, circled responses, or the percentage.

As previously stated, the areas of Health, Religion, and Personality were anticipated to register a lower rate of response. Problems related to Health ranked seventh of the nine problem categories in both underlined and circled responses. The area of Religion was shown to be eighth of the nine categories in underlined items, and lowest in the other two measures. Concerns with Religion were assumed by the researchers to reflect a more introspective focus which is characteristic of later years (Jung, 1933; Neugarten and Rosen, 1964).

Contrary to anticipated low response in the area of Personality, this category ranked highest of all concerns in both underlined and circled items, and fourth in the ratio between the two. This response may be speculated to reflect a biased sample. Mental Health Centers offer prescribed services designed to meet the needs of people experiencing 
"personality" problems. This may account for the consistent prioritizing of this category as a concern in this sample.

\section{Other Variables}

In order to investigate the possible influence of the variable of income on problem area, age distinction was ignored and the sample was divided into the following income categories: $\quad \$ 0-3,999,(\mathrm{~N}=13) ; \quad \$ 4,000-11,999(\mathrm{~N}=8) ;$ and $\$ 12,000$ and above, $(\mathrm{N}=7)$. Differences were identified in the areas of Occupation, Economic Security, and Religion. Occupation was identified as the third highest concern of the middle income group while ranking among the lowest for both the low and high income group. Economic Security was listed among the highest concerns for both the low and middle income groups, and did not appear among the top concerns of the highest income group. It is interesting to note that while Religion appears as a high concern for those with high incomes, it was accorded little priority for both groups of lesser income. In summary, for this sample, women with low and middle incomes tended to voice more concern with economic security and occupation, while women with the highest incomes showed a characteristic concern with religion.

The variable of marital status was categorized into Single, Married, and Separated/Divorced women. Differences within this variable were identified in the categories of Home and Family, Economic Security, and Religion. Concerns in the area of Home and Family were found to be of high 
importance for both the Married and Separated/Divorced women. Once again, Personality was among the top concerns for all groups. As indicated in the findings, women who are separated/Divorced expressed a significantly higher number of responses in both underlined and circled items than either of the other two groups. These women also ranked highest when measuring the percentage of critical to general concerns. Also of interest is the fact that Single women expressed fewer total problems in all three measures. In summary, the findings of this study suggest that marital status does impact to some extent on problem area and certainly bears great influence on the total number of problems expressed.

In regard to the variable of employment status, no significant relationship was found between this variable and problem area. However, as with marital status, a relationship does exist between employment status and quantity of items identified as problems. Unemployed women in this sample showed a higher number of total problems in all three measurements than their employed counterparts. They also underlined and circled more items in all problem areas except Courtship and Occupation.

No significant relationship was identified between the final variable, number of children, and problem area. Interpretation of this variable was limited due to the very small sample sizes for women with two or more children. 
RECOMMENDATIONS

The recommendations will be divided into two parts and will include recommendations for future research, and suggested applications of the findings of this study. Recommendations for follow-up research will concentrate on enlarging the sample while maintaining the design.

One method of enriching the sample would be to contact women who are seeking counseling in other settings than outpatient mental health centers, such as private clinicians and psychiatric hospitals. In order to apply these findings broadly and within a prevention framework a non-client population must be sampled and compared. From the experience of this research, it could be anticipated that enlisting interest and co-operation in collecting data might demand a significant proportion of total research effort. Through enlarging the sample in this manner, it would be hoped to involve more 40 year old women. It is of interest to note that only a small number of women in this age category requested services from the agencies involved in this study, and it would be of importance to investigate whether the small ratio is consistent throughout the year in these agencies and to compare this with other agencies. If this ratio is consistent two essential research issues arise: 1) where do 40 year old women turn for counseling, and 2) how can outpatient settings meet their needs. An additional suggestion for further research is to expand the time frame in which 
data is collected in order to control for possible seasonal influence on service requests. Finally, this research design might be used to sample a population of men for study and/or comparison.

The design employed was found to be especially congruent with the intention of this study, and replication of this design is encouraged. The Mooney Problem Checklist is particularly suited to the values of this research in that it is brief, non-obtrusive, and has been demonstrated to be beneficial to both client and therapist as an effective pretreatment tool. Other salient features of this instrument are that it spans a wide range of problem areas, and has been demonstrated to be an effective research tool.

Another important aspect of the design of this research is the consistent timing of administration of the instrument, which maximized reliability. The concept of sampling two separate age groups could enable a distinct comparison. Finally, the area of research in adult development is timely, relevant, and congruent with the current emphasis on education and prevention in the field of mental health.

Suggested applications of the findings of this study include use at individual, program, and community levels. The researchers as clinicians have experienced benefit at the individual level through increased awareness of developmental issues as an influence on personal problems. This heightened awareness may then be translated to more effective treatment. 
At the program level, these findings may be utilized in reflecting client needs by developing services particularly relating to developmental issues and transitional stress. This framework also serves to emphasize life-long transition and growich rather than focusing on problems as ruptures in mental health. These findings may also be used in an educational and preventive model at the community level with the goals of providing information, decreasing stigma traditionally attached to receipt of mental health services, and thereby discouraging individual isolation which often accompanies problems-in-living. 
FOOTNOTES

${ }^{1}$ L.R. Goulet and Paul B. Bates, Life Span Developmental Psychology Research and Theory (New York: Academic Press, 1970), p. 43.

\section{Ibid.}

${ }^{3}$ Gail Sheehy, Passages: Predictable Crises of Adult Life (New York: E.P. Dutton and Co., Inc., 1974), p. 13.

${ }^{4}$ Jolande Jacobi, The Way of Individuation (New York: Harcourt, Brace and World, Inc., 1967), p. 25.

${ }^{5}$ Ibid.

${ }^{6}$ Carl G. Jung, The Stages of Life, in Modern Man in Search of a Soul (New York: Harcourt, Brace and Company, 1933), pp. 114-11.5.

\section{${ }^{7}$ Ibid.}

${ }^{8}$ Erik H. Erikson, Childhood and Society (New York: W.W. Norton and Company, Inc., 1950), p. 266.

${ }^{9}$ Ibid.

${ }^{10}$ Bernice L. Neugarten, "The Awareness of Middle Age," in Middle Age and Aging: A Reader in Social Psychology, ed. by Bernice L. Neugarten (Chicago: The University of Chicago Press, 1968), p. 99.

\section{${ }^{11}$ Daniel J. Levinson,"} " in Middle Age and Aging: A Reader in Social Psychology, ed. by Bernice L. Neugarten (Chicago: The University of Chicago Press, 1968), pp. 21-25.

12 Gail Sheehy, Passages: Predictable Crises of Adult Life (New York: E.P. Dutton and Company, Inc., 1974), pp. 84-89. 


\section{${ }^{13}$ Ibid.}

14 Roger Gould, M.D., "The Phases of Adult Life: A Study in Developmental Psychology," American Journal of Psychiatry, Vol. 129, No. 5 (Nov. 1972), pp. 521-531.

15 Bernice L. Neugarten and Jacqueline Rosen, "Ego Functions in the Middle and Later Years: A Thematic Apperception Study," in Middle Age and Aging: A Reader in Social Psychology, ed. by Bernice Neugarten (Chicago: The University of Chicago Press, 1968), p. 99. 


\section{BIBLIOGRAPHY}

American Association of Marriage and Family Counselors, Multiregional Conference. Adult Life Passages. Portland, Oregon; April 14- $\overline{16,1978 . ~}$

Applegarth, Adrienne. "Some Observations on Work Inhibitions in Women." Journal of the American Psychoanalytic Association. Volume 24, Number 5, (Supplement 1976), pp. 251-268.

Bocknek, Gene. "A Developmental Approach to Counseling Adults." The Counseling Psychologist. Volume 6 , Number 1 , (1976), pp. 37-40.

Buros, Oscar. The Sixth Mental Measurements Yearbook. New Jersey: The Grayphon Press, 1965.

Bortner, Raymond. "Adult Development or Idiosyncratic Change? A Plea For The Developmental Approach." Gerontologist. Volume 6, Number 3, Part 1, (1976), pp. 159-164.

Bühler, Charlotte. From Birth to Maturity: An Outline of the Psychological Development of the Child. New York, 1935.

Bühler, Charlotte. "The Course of Human Life as a Psychological Problem." Human Development. Volume 11, Number 1, (1968), pp. 184-200.

Birren, James E., ed. Human Aging: A Biological and Behavioral Study. Washington, D.C.: U.S. Government Printing office, 1963.

Chesler, Phyllis. Women and Madness. New York: Doubleday, 1972 .

Dohrenwend, Bruce P., and Dohrenwend, Barbara S. Social Status and Psychological Disorder: A Casual Inquiry. New York: Wiley Interscience, 1969.

Ellis, Humphrey F. Mediatrics: Or the Characteristics, Importance, and Proper Care of the Middle Aged. New York: Morrow, 1962 .

Erikson, Erik H. Childhood and Society. New York: W.W. Norton and Co., 1950. 
Erikson, Erik H. "Generativity and Ego Identity." In Middle Age and Aging: A Reader in Social Psychology, edited by Bernice Neugarten. Chicago: The University of Chicago Press, (1968), pp. 85-87.

Erikson, Erik H. "Identity and the Life Cycle." Psychological Issues. Volume 1, Number 1, (1959).

Frenkel-Brunswik, Else. "Adjustments and Reorientation in the Course of the Life Span." In Middle Age and Aging: A Reader in Social Psychology, edited by Bernice Neugarten. Chicago: The University of Chicago Press, (1968).

Geoghegan, Barbara. Developmental Psychology: A Study of the Human Life Spiral. Milwaukee: Bruce Publishing Co., 1963.

Gould, Roger, M.D. "Adult Life Stages: Growth Toward SelfTolerance." Psychology Today. (Feb. 1975), pp. 74-78.

- "The Phases of Adult Life: A Study in Developmental Psychology." American Journal of Psychiatry. Vol. 129, No. 5, (Nov. 1972), pp. 521-531.

Goulet, L.R., and Bates, Paul B. Life-Span Developmental Psychology Research and Theory. New York: Academic Press, 1970 .

Gruen, Walter. "Adult Personality: An Empirical Study of Erikson's Theory of Ego Development." Personality in Middle and Late Life: Empirical Studies. Edited by Bernice Neugarten, et als. Chicago: The University of Chicago Press, 1968.

Havinghurst, Robert J. "The Relative Importance of Social Class and Ethnicity in Human Development." Human Development. Vol. 19, No. 1, (1976), pp. 56-64.

Jacobi, Jolande. The Way of Individuation. New York: Harcourt, Brace and World, Inc., 1967.

Jung, Carl G. "Aims of Psychotherapy." Modern Man in Search of a Soul. New York: Harcourt, Brace and Company, 1933.

- "Marriage as a Psychological Relationship." Contributions to Analytical Psychology. New York: 1928.

- "The Stages of Life." Modern Man in Search of a Soul. New York: Harcourt, Brace and Company, 
Kastenbaum, Robert. "Theories of Human Aging: The Search for a Conceptual Framework." Journal of Social

Issues. Vol. 21 , No. 4, (1965), pp. 13-36.

Lee, Robert, and Casebier, Marjorie. The Spouse Gap: Weathering the Marriage Crisis During Middlescence. Abingdon Press, 1971 .

LeShan, Eda. Wonderful Crisis of Middle Age. New York: David McKay, 1973.

Levinson, Daniel J. "Growing Up With The Dream." Psychology Today. Vol. 11, No. 8, (Jan. 1978), pp. $20+$.

Lidz, Theodore. The Person: His Development Throughout the Life Cycle. New York: Basic Books, 1968.

Light, Bernard H., and Amick, Jean H. "Rorschach Responses of the Normal Aged." Journal of Projective Techniques. Volume 20, Number 2, (June 1956), pp. 185195 .

Lowerthal, Marjorie F., Thurnher, Majda, and Chiriboga, David. Four stages of Life: A Comparative study of Women and Men Facing Transitions. San Francisco: Jossey-Bass, 1975 .

Marmon, Judd. "The Crisis of Middle Age." American Journal of Orthopsychiatry. Vol. 37, No. 2, (1967), pp. 336-339.

Mooney, R.L., and Gordon, L.V. Manual to accompany the Mooney Problem Check Lists. New York: The Psychological Corporation, 1950.

Mussman, Milton C. "Middlescence: Critical Period or Periods in Adulthood." Dissertations Abstracts. Vol. 29, (1968), pp. $117 \overline{6 .}$

Neugarten, Bernice L. "Adaptation and the Life Cycle." The Counseling Psychologist. Vol. 6, No. 1, (1976), pp. 16-20.

- "Adult Personality: A Developmental View." Human Development. Vol. 9; (1966), pp. 6-73.

"Adult Personality: Toward a Psychology of the Life Cycle." In Middle Age and Aging: A Reader in Social Psychology, edited by Bernice Neugarten. Chicago: The University of Chicago Press, 1968. 
"Continuities and Discontinuities of Psychological Issues Into Adult Life." Human Development. Vol. 12, (1969), pp. 121-1 30 .

"The Awareness of Middle Age." In Middle Age and Aging: A Reader in Social Psychology, edited by Bernice Neugarten. Chicago: The Üniversity of Chicago Press, 1968.

, and Rose, Jacqueline L. "Ego Functions in the Middle and Late Years: A Thematic Apperception Study." In Middle Age and Aging: A Reader in Social Psychology, edited by Bernice Neugarten. Chicago: The University of Chicago Press, 1968, 99. 90-101.

Neumann, Erich. "Self-Realization of Centroversion in the Second Half of Life." The origins and History of Consciousness. New Jersey: Princeton University Press, 1954 .

Peck, Robert C. "Psychological Developments in the Second Half of Life." In Middle Age and Aging: A Reader in Social Psychology, edited by Bernice Neugarten. Chicago: The University of Chicago Press, 1968.

Rappaport, David, ed. Organization and Pathology of Thought: Selected Sources. New York: Columbia Press, 1951.

Sheehy, Gail. Passages: Predictable Crises of Adult Life. New York: E.P. Dutton, 1974.

Sheehy, Gail. "Why Mid-Life is Crisis Time For Couples." New York. Vol. 7, (April 1974), pp. 31-35.

Thompson, Albert S. "Counseling and the Ages of Man." Journal of Counseling Psychology. Vol. 11, No. 3, (1964), pp. 221-229.

Ticho, Gertrude R. "Female Autonomy and Young Adult Women." Journal of the American Psychoanalytic Association. Vol. 24, No. 5, (1976), pp. 139-155.

Vedder, Clyde B. Problems of the Middle-Aged. Springfield, Illinois: C.C. Thomas Publishing Co., 1965. 
APPENDIX A

$\mathrm{Hi}$ !

We'd like to ask you to take a few minutes to help us out. The process can remain entirely confidential, and is focused on making programs like this more relevant to your needs. In connection with the Portland State University School of Social Work, we are doing research about women and their concerns. This agency is sponsoring us in asking you to complete the attached checklist. The checklist is a series of problem statements -- some may be concerns to you while others may not.

To complete the checklist would you first read through the statements and underline those that presently trouble you. Then look back over the ones you underlined and circle the numbers of the statements that trouble you most. Finally, would you briefly answer the 3 questions on the last page.

This checklist takes most people about 20-30 minutes, and many who have completed the checklist have found it to be very helpful in clarifying their problems. If you choose, a copy can be given to your counselor. This may be helpful to him/her in better understanding you and your concerns. Please check with the secretary about this. Don't put your name on the form and in this way we'll insure that your responses are confidential. Do answer the other information on the front page -- we're wondering how your concerns relate to age, income, and marital status. Our intent is that this research will be useful in developing awareness and programs that are relevant to your needs.

Thanks for your co-operation!

Joyce Carey

Linda M. Rodgers 


$$
\text { hinese. }
$$

Date.

Occupation. Sex

Marital Status No. of Children

\section{Gross Howsenold Inoome}

Following you will find a list of problems with which people are often faced - problems relating to health, work, family, temperament, and so on. You are to read through the list and to select those statements that represent your problems. Mark the list honestly and sincerely and you will obtain a representative inventory of your problems. Remember, this is not a test. There are no right or wrong answers. The statements that you are to underline are those that refer to you. You are assured that what you mark in the inventory will be treated in the strictest of confidence. There are three steps for you to take.

Pirst Step: Read slowly through the list and underline each problem that suggests something that is troubling you, thus "1. Feeling tired much of the time."

Second Step: After you have gone through the entire list, look back over the problems that you have underlined and circle the numbers in front of those problems that are of most concern to you, thus "1. Feeling tired much of the time."

Third Step: Reply to the summarizing statements on page 5.

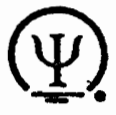

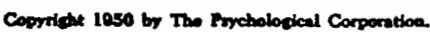

All ngthe reserved. No part of this check list way be reproduced in any form of printing or by any other meams, electronic or mechanical. induding. but not limited to, photocopying, audiovisual recording and cranumisuton, and portrayal or duplication in any intormation storage and retrieval optem, without permistion in writing trom the publisher. 
Firet Step: Read the liat slowly, and as you come to a problem which troubles you, underline it.

1. Feeling tired much of the time

2. Sleeping poorly

3. Too much underweight or overweight

4. Gradually losing weight

5. Frequently bothered by a sore throat

6. Catching a good many colds

7. Living in an undesirable location

8. Transportation or commuting problem

9. Lacking modern conveniences in my home

10. Lacking privacy in my living quarters

11. Unfair landlord or landlady

12. Poor living conditions

13. Wanting to develop a hobby

14. Wanting to improve myself culturally

15. Wanting worthwhile discussions with people

16. Wanting to learn how to dance

17. Lacking skill in sports or games

18. Not knowing how to entertain

19. Lacking leadership ability

20. Lacking self-confidence

21. Not really being smart enough

22. Being timid or shy

23. Lacking courage

24. Taking things too seriously

25. Wanting a more pleasing personality

26. Awkward in meeting people

27. Daydreaming

28. Being too tall or too short

29. Being physically unattractive

30. Wishing I were the other sex

31. Being away from home too much

32. Member of my family in poor health

33. Death in my family

34. Member of my family working too hard

35. Worried about a member of my family

36. Drinking by a member of my family

37. Having too few dates

38. Not finding a suitable life partner

39. Dociding whether I'm really in love

40. Having to wait too long to get married

41. Being financially unable to get married

12. In love with someone my family won't accept

43. Needing a philosophy of life

44. Confused in my religious beliefs

45. Losing my earlier religious faith

46. Having beliefs that differ from my church

47. Failing to see the relation of religion to life

48. Differing from my family in religious beliefs
49. Poor appetite

50. Stomach trouble (indigestion, ulcers, etc.)

51. Intestinal trouble

52. Poor complexion or skin trouble

53. Poor posture

54. Feet hurt or tire easily

55. Needing a job

56. Needing part-time work

57. Disliking financial dependence on others

58. Having too many financial dependents

59. Getting into debt

60. Fearing future unemplayment

61. Having a poor memory

62. Not being as efficient as I would like

63. Not using my leisure time well

64. Too few opportunities for meeting people

65. Trouble keeping up a conversation

66. Not mixing well with the opposite sex

67. Being lazy

68. Lacking ambition

69. Being influenced too easily by others

70. Being untidy

71. Being too careless

72. Not doing anything well

73. Feeling ill at ease with other people

74. Avoiding someone I don't like

75. Finding it hard to talk before a group

76. Worrying how I impress people

77. Not getting along well with people

78. Not really having any friends

79. Having to live with relatives

80. Irritated by habits of a member of my family

81. Home untidy and ill kept

82. Too much quarreling at home

83. Too much nagging and complaining at home

84. Not really having a home

85. Wondering whether to go steady

86. Deciding whether to become engaged

87. Deciding whether to get married

88. Needing advice about getting married

89. Wondering if I really know my prospective mate

90. Afraid of the responsibilities of marriage

91. In love with someone of a different religion

92. Finding church services of no interest to me

98. Doubting the value of prayer

94. Doubting the existence of Cod

95. Science conflicting with my religion

96. Not getting satisfactory answers from religion 
97. Having a permanent illness or disability

98. Frequent nose or sinus trouble

99. Having trouble with my ears or hearing

100. Allergies (asthma, hayfever, hives, etc.)

101. Having trouble with my eyes

102. Having a serious illness or disease

103. Needing financial assistance

104. Can't seem to make ends meet

105. Not getting a satisfactory diet

106. Not having enough money for necessities

107. Never being able to own a home of my own

108. Having too many financial problems

109. Wanting to improve my mind

110. Wanting to improve my appearance

11. Wanting to improve my manners or etiquette

112. Having trouble with my speech

113. Forgetting the things I learned in school

114. Having trouble understanding what I read

115. Speaking or acting without thinking

116. Being rude or tactless

117. Being stubborn or obstinate

118. Sometimes acting childish or immature

119. Being envious or jealous

120. Tending to exaggerate too much

121. Being disliked by someone

122. Being left out of things

123. Being made fun of or teased

124. Being treated unfairly by others

125. Suffer from racial or religious prejudice

126. Having feelings of extreme loneliness

127. Not being understood by my family

128. Not being trusted by my family

129. Feeling rejected by my family

130. Having an unhappy home life

131. Wanting love and affection

132. Boing an only child

133. Disappointed in a love affair

134. Too deeply involved in a love affair

135. Having to break up a love affair

136. In love with someone I can't marry

137. Caring for more than one person

188. Afraid of losing the one I love

159. Not going to church often enough

140. Wanting to feel close to God

141. Wondering if there is life after death

142. Troubled by lack of religious faith in others

143. Upset by arguments about religion

144. Differing with my husband or wife over religion
145. Troubled by headaches

146. Glandular disorders (thyroid, lymph, etc.)

147. Menstrual or female disorders

148. Kidney or bladder trouble

149. Muscular aches and pains

150. High blood pressure

151. Not enough money for medical expenses

152. Too little money for recreation

153. Needing money for education or training

154. Unsure of future financial support

155. No steady income

156. Work too irregular or unsteady

157. Needing more exercise

158. Needing more outdoor air and sunshine

159. Wanting more personal freedom

160. Wondering if further education is worth while

161. Wishing I had a better educational background

162. Wanting to read worthwhile books more

163. Too self-centered

164. Getting into arguments or fights

165. Disliking certain persons

166. Sometimes lying without meaning to

167. Feeling blue and moody

168. Trying to forget an unpleasant experience

169. Not knowing the kind of person I want to be

170. Confused as to what I really want

171. Feeling I am too different

172. People finding fault with me

173. Feeling no one cares for me

174. Sometimes feeling life is hardly worth while

175. Too much interference by relatives

176. Having too many decisions made for me

177. Unable to discuss certain problems at home

178. Not getting along with a member of my family

179. Educational level different from my family's

180. Wishing I had a different family background

181. Petting and necking

182. Thinking too much about the opposite sex

183. Wondering how far to go with the opposite sex

184. Finding it hard to control sex urges

185. Repelled by thoughts of sexual relations

186. Needing information about sex

187. Lacking necessary experience for a job

188. Not knowing how to look for a job

189. Needing to know my vocational abilities

190. Unable to enter my chosen vocation

191. Doubting the wisdom of my vocational choice

192. Combining marriage and a career 
Page 4

198. Having considerable trouble with my teeth

194. Occasionally feeling faint or dizzy

195. Troubled by swelling of the ankles

196. Trouble with my scalp

197. Occasional pressure or pain in my head

198. Not getting enough rest or sleep

199. Not budgeting my money

200. Not having a systematic savings plan

201. Buying too much on the installment plan

202. Being too extravagant and wasteful

203. Living far beyond my means

204. Having to spend all my savings

205. Wanting more chance for self-expression

206. Little chance to enjoy art or music

207. Little opportunity to enjoy nature

208. Not having enough time for recreation

209. Wanting very much to travel

210. Needing a vacation

211. Mind constantly wandering

212. Constantly worrying

213. Too easily moved to tears

214. Too nervous or high strung

215. Having a bad temper

216. Feelings too easily hurt

217. Unable to express myself well in words

218. Feeling inferior

219. Not reaching the goal I've set for myself

220. Having difficulty in making decisions

221. Feeling I am a failure

222. Wanting to be more popular

223. Mother or father not living

224. Parents separated or divorced

225. Having clashes of opinion with my parents

226. Parents sacrificing too much for me

227. Parents having a hard time of it

228. Not seeing parents often enough

229. Being too inhibited in sex matters

230. Being underdeveloped sexually

231. Too easily aroused sexually

232. Thinking too much about sex matters

233. Fear of having a child

234. Lacking sex appeal

235. Working too hard

236. Getting no appreciation for the work I do

237. Finding my work too routine or monotonous

238. Wanting more freedom in my work

239. Would rather be doing other kind of work

240. Unsatisfactory working conditions
241. Bothered by shortness of breath

242. Having heart trouble

243. Having a persistent cough

244. Needing an operation or medical treatment

245. Needing another climate for my health

246. "Change of life" (menopause)

247. Needing legal advice

248. Needing to make a will

249. Needing an insurance program

250. Needing advice about investments

251. Wanting to have a business of my own

252. Worried about security in old age

253. Not having enough social life

254. Being alone too much

255. Missing my former social life

256. Not entertaining often enough

257. Spending too many evenings at home

258. Not living a well-rounded life

259. Unhappy too much of the time

260. Sometimes feeling things are not real

261. Bothered by thoughts running through my head

262. Sometimes afraid of going insane

263. Bothered by thoughts of suicide

264. Sometimes feeling forced to perform certain acts

285. Having a troubled or guilty conscience

266. Afraid of being found out

267. Sometimes being dishonest

268. Having a certain bad habit

269. Wanting to break a bad habit

270. Giving in to temptation

271. Worrying whether my marriage will succeed

272. Having different interests from husband or wife

273. Marriage breaking apart

274. Needing advice about a marriage problem

275. Needing advice about raising children

278. Wanting to have a child

277. Having unusual sex desires

278. Bothered by sexual thoughts or dreams

279. Worried about the effects of masturbation

280. Sexual needs unsatisfied

281. Sexually attracted to someone of my own sex

282. Sexual desires differ from husband's or wife's

283. Being bothered or interfered with in my work

284. Not liking some of the people I work with

285. Family disapproves of my present job

286. Dissatisfied with my present job

287. Poor prospects of advancement in my present job 288. Afraid of losing my job

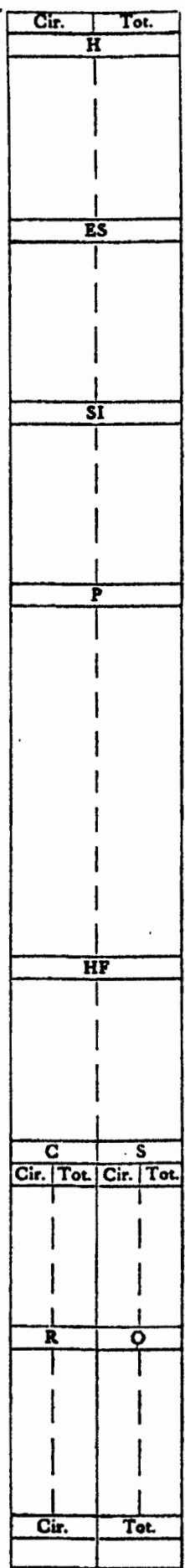

Toral .... 
Thind Step: Reply to the following.

\section{SUMMARY}

1. Use the space below to indicate any additional problems that you may have.

2. Write a brief summary of what you consider to be your chief problems.

3. Would you like to talk to someone about some of your problems? 
Pege 6 


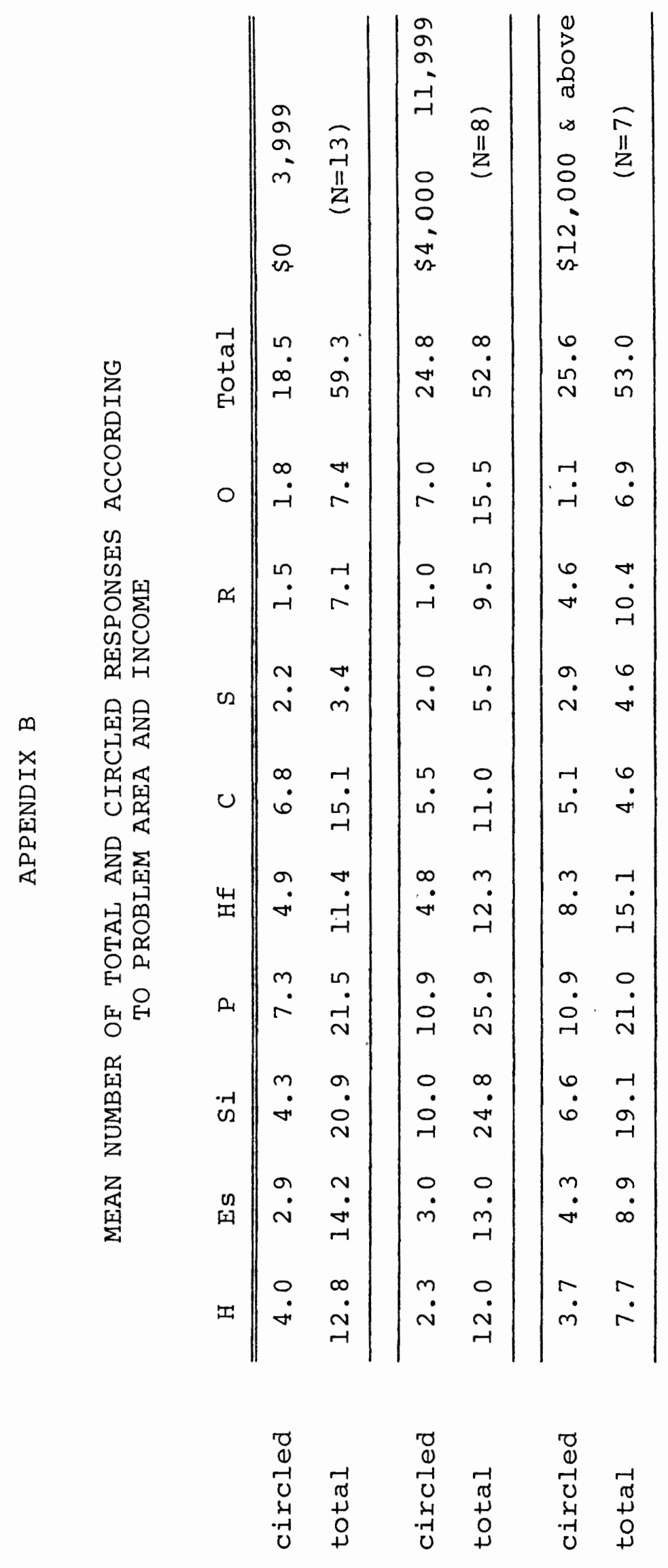




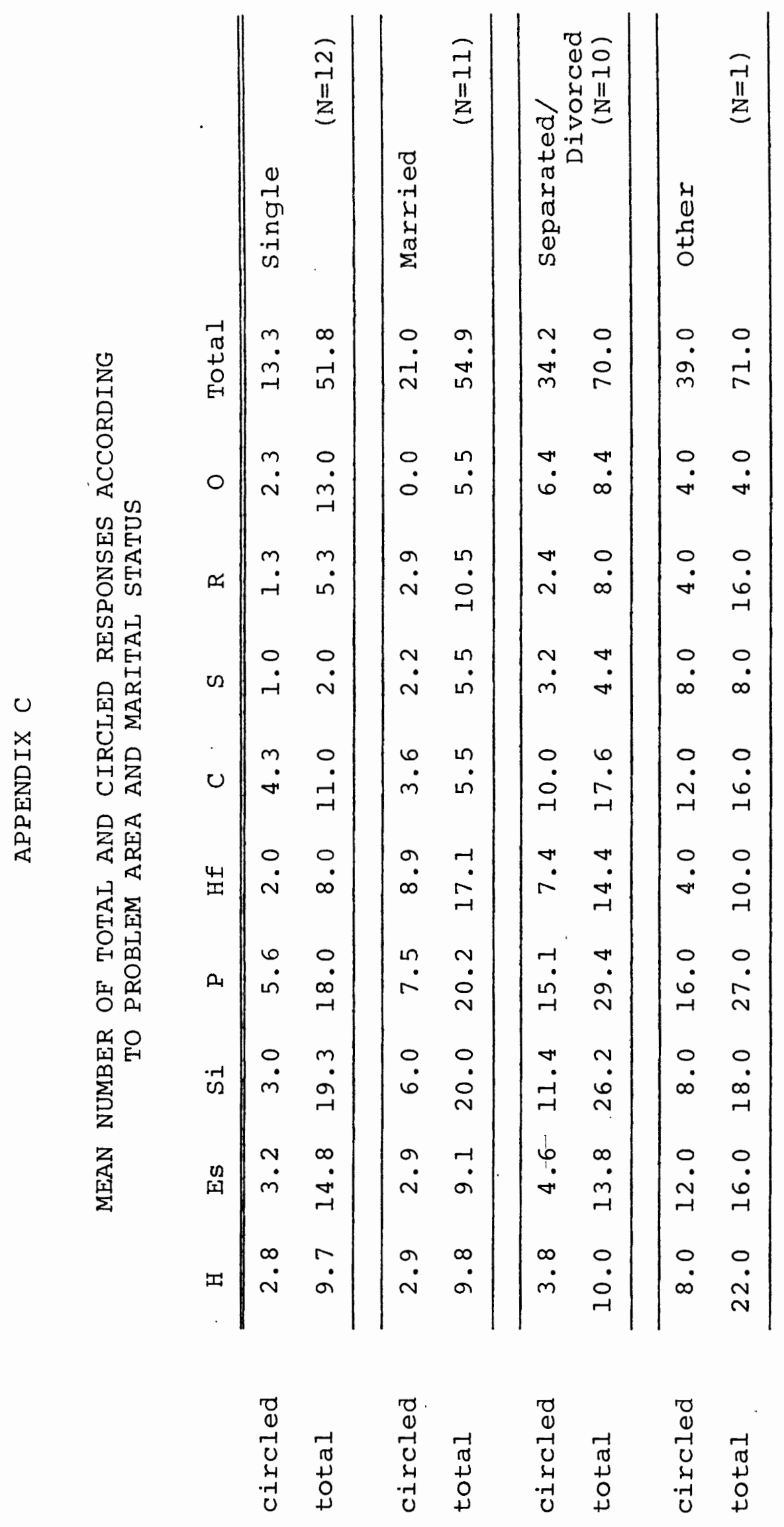




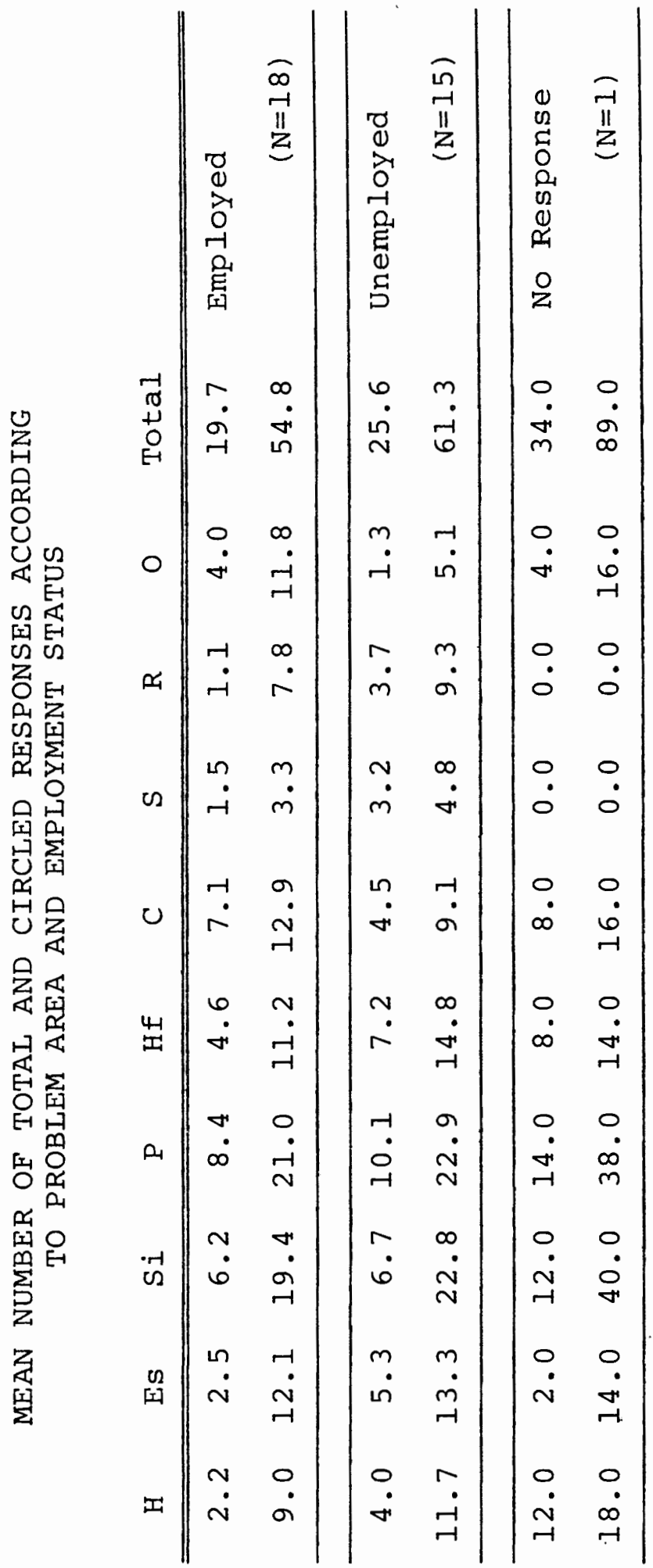

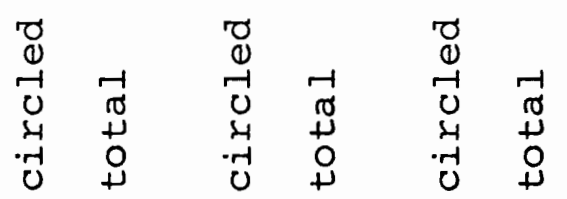




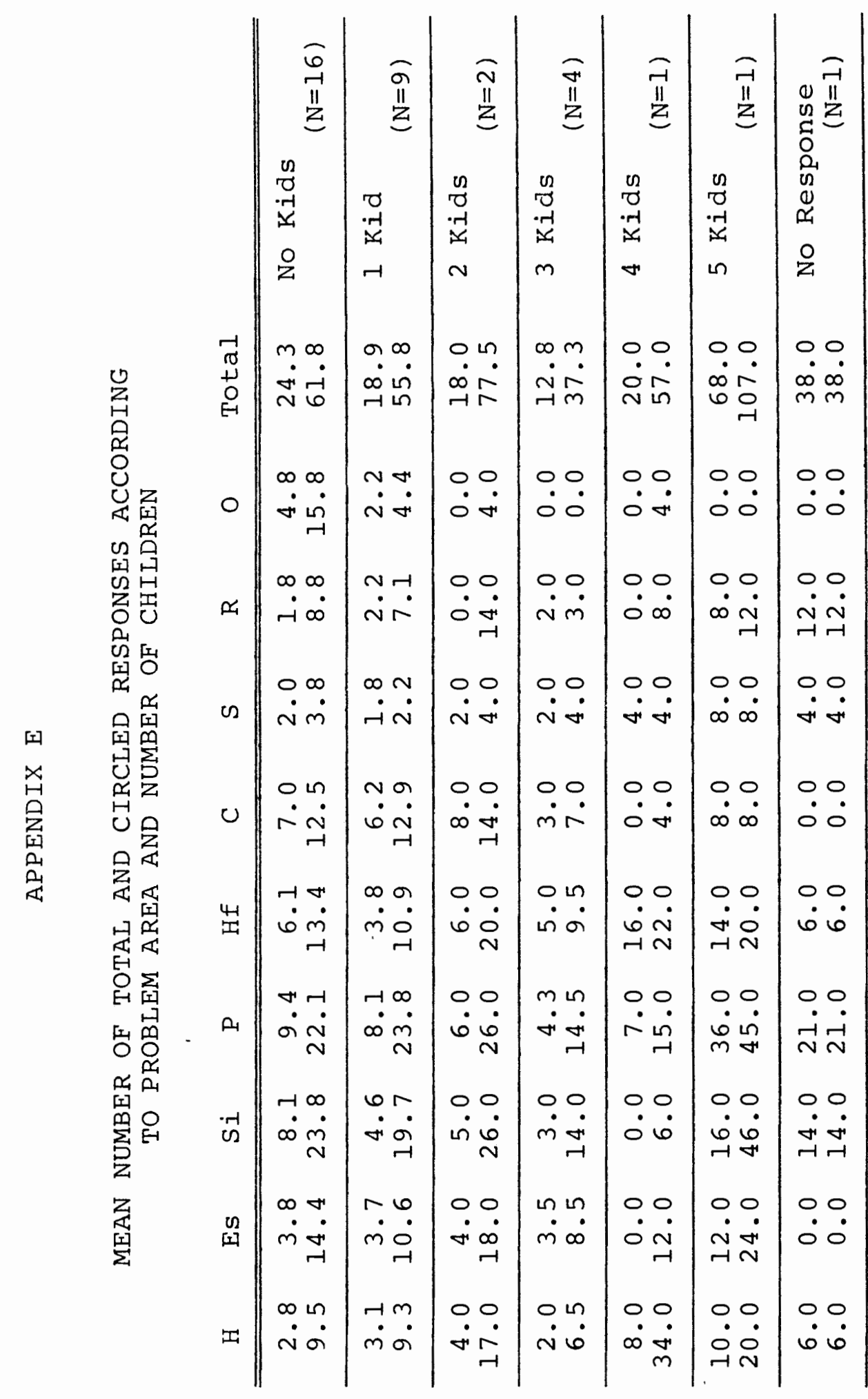

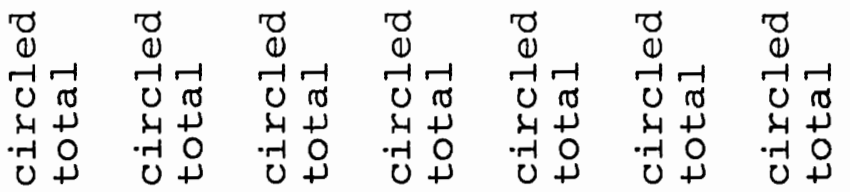

